with dark-coloured blood, but seemed otherwise apparently in a healthy state, though it was twice its natural size. The intestines were, for the most part, in a healthy state, excepting the lower part of the ileum, which was in a high state of inflammation, and in some places seemed to be in the first stage of gangrene; the calibre of the bowels at this place was very much diminished by the great thickness of their parietes, which were one-third of an inch thick. There was no urine in the bladder, but the rectum contained a little hardened fæees. Some flakes' of coagulated lymph floated about in the cavity of the abdomen.

The subject of the preceding sketch was a foreman in an extensive manufactory of bichromate of potash and nitrate of lead, besides many other chemical products. The gases \&c. arising from the several processes conducted were said by the workman to be very noxious, and the above patient always complained of a smarting pain in the pit of his stomach whenever he inhaled any of them.

One very striking effect which this kind of employment has on the workmen is; that by successive ulcerations the septum nasi has, in many instances, been perforated to the extent, in some, of the size of a shilling.

The most extraordinary part of this case is the immense size of the liver, which was certainly the largest $I$ have ever had the opportunity of seeing; but the inflammation of the stomach and bowels was no doubt the immediate cause of death.

It would be interesting to determine whether the man's employment had any effect in the development of this disease, both as regards the liver and the inflammatory state of the intestinal canal. If any of the readers of THE LANCET could furnish any analogous case in elucidation of the above, it would be taken as a great favour.

Chapel-street, Salford, 1851 .

\section{ON $\Lambda$}

\section{CASE OF CHRONIC HYDROCEPHALUS.}

By H. ROWLAND HOSKINS, Esq., M.R.C.S., Hoxton. A CHILD, two years of age, was brought to me on the 14 th of October, 1850 , suffering from chronic hydrocephalus. The history was as follows: For the first three months after birth she had frequent convulsive fits, but after that period they became less frequent; she appeared to thrive, learned to speak a few words, and to walk, and appeared to be in good health. When eighteen months old she had a fall and struck the back. of her head. From that time she lost the power of speaking and walking; her head began to enlarge, and the child became worse and worse, and more and more idiotic in her appearance and manners. When I first saw her she was lying with the eyes half closed, apparently sleeping, but constantly grating the teeth and rolling the head. The mother informed me that this was her usual state, but that twice or three times a day she would scream violently for an hour and a half or two hours; and then relapse into torpor. She never gave any signs of consciousness, merely swallowing food when it was placed in. her mouth. Convulsive fits occurred about three times in a week. The head measured serenteen inches in circumference; there were two large prominences at the posterior part, one also over each ear; the forehead was very prominent; the pupils were dilated, and the movements of the iris very: sluggish; the skin was cool and dry; pulse 160; tongue dry and whitish; bowels much confined. The mother had taken: the child, for the last two months, to a large hospital, but was obliged to relinquish her attendance there, as motion 'was very distressing to the patient.

As this case had been under the care of a physician whose name was a sufficient guarantee that the usual remedies had had a judicious trial, I thought myself justified in trying a new mode of treatment. I therefore ordered half a grain of iodide of potassium to be given every four hours, and five grains of compound scammony powder at night, when the bowels required it. (The latter was only given twice-on the first and fourth nights.)

For the first four days the only apparent effect was a gradual diminution of frequency in the pulse, which sunk to 140 , but after that time there was evident and progressive improvement. The unnatural prominences on the head began to diminish; the screaming fits became shorter and less frequent, as did the convulsions; the rolling of the head was no longer constant; the irides became more active. After a fortnight's continuance of the treatment, the head measured fifteen

inches, the child slept quietly, and when awake, appeared sensible, recognising its parents, and making signs for food; the animal functions were all well performed; the patient was rapidly gaining flesh. The iodide of potassium was continued until the 2nd of November, when the child appeared perfectly well; the head then measured fourteen inches.

Since that time fits of screaming have recurred twice, but yielded immediately to a repetition of the medicine. I saw her last on the 14th of December, when she seemed quite well, and as intelligent as most children of her age.

February, 1851 .

\section{A ftrírrar \\ OF THE PRACTICE OF}

\section{MEDICINE AND SURGERY IN THE \\ HOSPITALS OF LONDON.}

Nulla est alia pro certo noseendi via, nisi quam plurimas et morborum, et dissectionum historias, tum aliorum proprias, collectas habere et inter s
comparare.-Morgaani, De Sed. et Caus, Morb., lib. 14. Procmium.

\section{ST. BARTHOLOMEW'S HOSPITAL. \\ Thyroid Hernia; Death; Autopsy.}

(Under the care of Mr. Stranley.)

IT las been maintained that diagnosis is both the most essential and difficult part in the practice of medicine and surgery. Many of our professional brethren will doubtless agree that this assertion is founded on truth, and will con. gratulate themselves that so many additional means have in modern times been devised for rendering the diagnosis of disease more accurate and satisfactory. The stethoscope, chemical analysis, the microscope, \&c., are rendering services which come daily under observation; but there are still certain affections which elude our most careful investigations. In medicine, nervous complaints might be named among these, and in surgery the diagnosis of tumours, of malignant disease, and of certain forms of hernia.

Inguinal, femoral, and umbilical hernia present very distinct and well-defined characters, yet these affections may sometimes remain doubtful, and even be mistaken one for the other. Indeed, we were lately told by an accomplished hospital surgeon, that a patient was a short time ago sent to him with a varicose state of the vena saphena near the groin, which vascular derangement had all the characters of femoral hernia; so much so, that by the advice of a very talented surgeon, a truss had been worn for it. Ventral, cystic, and vaginal hernia are still more difficult to recognise; and we may lastly say, that the existence of thyroid hernia can hardly be observed in the living subject. Nor is this latter circumstance to be wondered at, as it is stated by an eminent author on hernia, that it is hardly possible that a tumour can form on the thigh. Mr. Lawrence expresses himself as follows in speaking of thyroid hernia:- "The pectinæus, the long and middle head of the triceps, and the gracilis, so completely close the space into which the sac protrudes, that they must by their pressure prevent it from increasing to any great bulk."........" These circumstances of anatomical position would undoubtedly lead us to suppose that the complaint could never be recognised during life. Yet we are informed by Garengeot, that Arnaud had reduced several obturator hernix, and kept them up by bandages; that he himself had seen and reduced two such ruptures in the living subject, and that two other instances had been communicated to the Academy. The careful perusal of these facts has not satisfied me that they were obturator hernise."

It is, then, quite apparent that a protrusion of bowel or omentum through the obturator foramen is not only extremely difficult to diagnose, but that such an occurrence is very rare. The case lately under the care of Mr. Stanley was surrounded by much obscurity, as the groin presented appearances which might in some degree account for the symptoms. In offering the subjoined report, we have no doubt that it will add one more valuable fact regarding the history of unusual abdominal displacements.

Eliza T-, aged fifty years, was admitted April 3, 1851, under the care of Mr. Stanley. The patient is a widow, has borne several children, and says that she never suffered from 